\title{
STRUCTURAL EFFECTS OF HEAT TREATMENT HOLDING-TIME ON DYNAMIC AND DAMPING BEHAVIOUR OF AN Fe-28Mn-6Si-5Cr SHAPE MEMORY ALLOY
}

\author{
Mihai POPA ${ }^{1}$, Bogdan PRICOP ${ }^{1}$, Bogdan ISTRATE ${ }^{2}$, \\ Florin POPA ${ }^{3}$, Viorel GOANȚ $\breve{A}^{2}$, Leandru Gheorghe BUJOREANU ${ }^{1 *}$ \\ 1“Gheorghe Asachi” Technical University of Iași, Faculty of Materials Science and Engineering, Blvd. Dimitrie \\ Mangeron 61A, 700050 Iași, Romania \\ 2“"Gheorghe Asachi” Technical University of Iași, Faculty of Mechanical Engineering, Blvd. Dimitrie Mangeron \\ 61-63, 700050 Iași, Romania \\ ${ }^{3}$ Technical University of Cluj-Napoca, Faculty of Materials and Environmental Engineering, 400461 Cluj- \\ Napoca, Romania \\ *e-mail: leandru-gheorghe.bujoreanu@academic.tuiasi.ro
}

\begin{abstract}
The paper reports the structural effects of holding time period, during heat treatment, on the dynamic and damping behavior of a Fe-28Mn-6Si-5Cr (mass. \%) shape memory alloy. After casting and hot rolling, solution treatment at $1050{ }^{\circ} \mathrm{C}$ was applied for five holding times, 2, 4, 6, 8 and 10 hours, followed by water quenching. The specimens were analyzed by scanning electron microscopy and $X$ ray diffraction which emphasized that only the 2-hours solution treated specimens contained E-hexagonal close packed (hcp) martensite and experienced the highest internal friction value. These specimens were tested on a special device which transformed both tension and compression into tensile strain applied to the specimens and proved to be a promising solution for anti-seismic damper.
\end{abstract}

KEYWORDS: FeMnSiCr shape memory alloys, martensite, strain sweep dynamic mechanical analysis, internal friction, anti-seismic damper

\section{Introduction}

Fe-based shape memory alloys (SMAs) are less expensive [1], can develop higher recovery stresses [2] by constrained recovery shape memory effect (SME) [3] and are more easily processable [4] as compared to well-known NiTi SMAs, while achieving comparable corrosion resistance [5]. Polycrystalline Fe-(28-34)Mn-(4-6.5)Si (mass. \%, as all chemical compositions will be listed hereinafter) SMAs were reported ever since 1987 as experiencing an almost perfect SME [6].

The microstructural phenomenon that governs SME is the reversion of $\varepsilon$-hexagonal close-packed (hcp) stress induced martensite to $\gamma$-face centered cubic (fcc) austenite, during heating [7]. Besides $\varepsilon$ hcp, a (body centered cubic, bcc) martensite, designated as $\alpha^{\prime}$, can be thermally induced at low Mn contents [8] or stress induced at high deformation levels [9]. The common conviction is that $\alpha^{\prime}$ bcc martensite delays the reverse martensitic transformation $\varepsilon$-hcp $\rightarrow \gamma$-fcc, which diminishes SME magnitude in Fe-Mn-Si-based [10]. The most popular commercial applications of these alloys comprise: lock rings for bicycle frame pipes [11], pipe coupling rings [12], crane rail fasteners [13], concrete prestraining rods [14], embedded stripes for concrete beam curvature control [15], anti-seismic dampers for very tall buildings [16].

It is one special grade of commercial use, $\mathrm{Fe}$ $28 \mathrm{Mn}-6 \mathrm{Si}-5 \mathrm{Cr}$ [17], that has been mainly used in vibration mitigation applications [18], as it belongs to the inter-phase boundary type high-damping materials, in which internal friction (IF) is caused by the hysteretic movement of interfaces during the stress induced transformations [19]. Since both SME and IF are based on the reverse movement of $\gamma / \varepsilon$ interface [7], the relationship between these two phenomena, on one hand and stress-induced formation of $\varepsilon$-hcp martensite from $\gamma$-fcc austenite, on the other hand, has been intensely studied, in Fe-Mn based SMAs [20].

In a previous paper, a preliminary evaluation of holding time effects, during solution treatment, was 
performed and an exothermic precipitation phenomenon was observed around $500{ }^{\circ} \mathrm{C}$, especially after long holding periods. In addition, dynamic strain sweeps, performed by three-point-bending, caused fine shearing of martensite bands, associated with a noticeable decrease of internal friction [21].

The present paper aims to further investigate the connection between holding periods and dynamic and damping behavior of a Fe-28Mn-6Si-5Cr SMA, which will be tested on an experimental anti-seismic damper.

\section{Experimental procedure}

An Fe-28Mn-6Si-5Cr SMA alloy was melt in a levitation induction furnace, cast into ingots, longitudinally cut by wire spark erosion, hot rolled $\left(1050{ }^{\circ} \mathrm{C}\right)$ and solution treated at $1050{ }^{\circ} \mathrm{C}$ for five holding times: 2, 4, 6, 8 and $10 \mathrm{~h}$, with final water quenching.

Different specimens were cut with rectangular $(4 \times 25 \mathrm{~mm})$ and "dog-bone" $(4 \times 30 \mathrm{~mm}$-gauge $)$ geometries. The former was used for dynamic mechanical analysis (DMA) and structural investigations while the latter was used for damping tests on an anti-seismic damper.

DMA was performed, during five cycles, in the three-point-bending strain sweep mode (DMA-SS3PB), by means of DMA 242 Artemis NETZSCH device, using a frequency of $1 \mathrm{~Hz}$ and a strain amplitude increasing between 0.01 and $0.09 \%$. Considering that the first cycle usually corresponds to a transient phenomenon, it was removed from the diagrams and an averaging was performed, by PROTEUS software the DMA device has been equipped with.

The structural effects were examined using an Expert PRO MPD diffractometer with $\mathrm{Cu} \mathrm{K} \alpha$ radiation and a scanning electron microscope (SEM) JEOL JSM-5600LV device, equipped with an Oxford Instruments EDX (Energy dispersive X-ray spectrometry) detector (INCA 200 software). XRD patterns were recorded on the significance region $2 \theta$ $=40-100^{\circ}$. XRD maxima identification of $\gamma$-fcc, $\varepsilon^{-}$ hep and $\alpha^{\prime}$-bcc phases was done using crystallographic databases 01-071-8288, 01-071-8285 and 00-034-0396, respectively. SEM micrographs were recorded on specimens etched with a solution of $1.2 \% \mathrm{~K}_{2} \mathrm{~S}_{2} \mathrm{O}_{5}+1 \% \mathrm{NH}_{4} \mathrm{HF}_{2}$ in $100 \mathrm{~mL}$ distilled water.

In order to test the damping behavior of differently processed $\mathrm{Fe}-28 \mathrm{Mn}-6 \mathrm{Si}-5 \mathrm{Cr}$ SMA specimens, a special anti-seismic damper was designed and manufactured, based on a concept developed by Dolce et al. In Figure 1(a) the functioning principle of Dolce's damper is illustrated. It shows that, both during assembly's elongation and compression, the two specimens, fastened between the two transversal rods, are subjected to tensile strains. Considering that Dolce's damper was designed for NiTi wires [22], with small mechanical hysteresis, meant to dissipate seismic energy, the device was adapted for an even number of flat "dogbone" specimens that have larger mechanical hysteresis (therefore are able to dissipate larger amounts of energy). In addition, $\mathrm{Fe}-28 \mathrm{Mn}-6 \mathrm{Si}-5 \mathrm{Cr}$ SMA experienced an excellent low-cycle fatigue life, exceeding 28,000 cycles at a tensile dynamic stress of $773 \pm 193 \mathrm{MPa}$ [23]

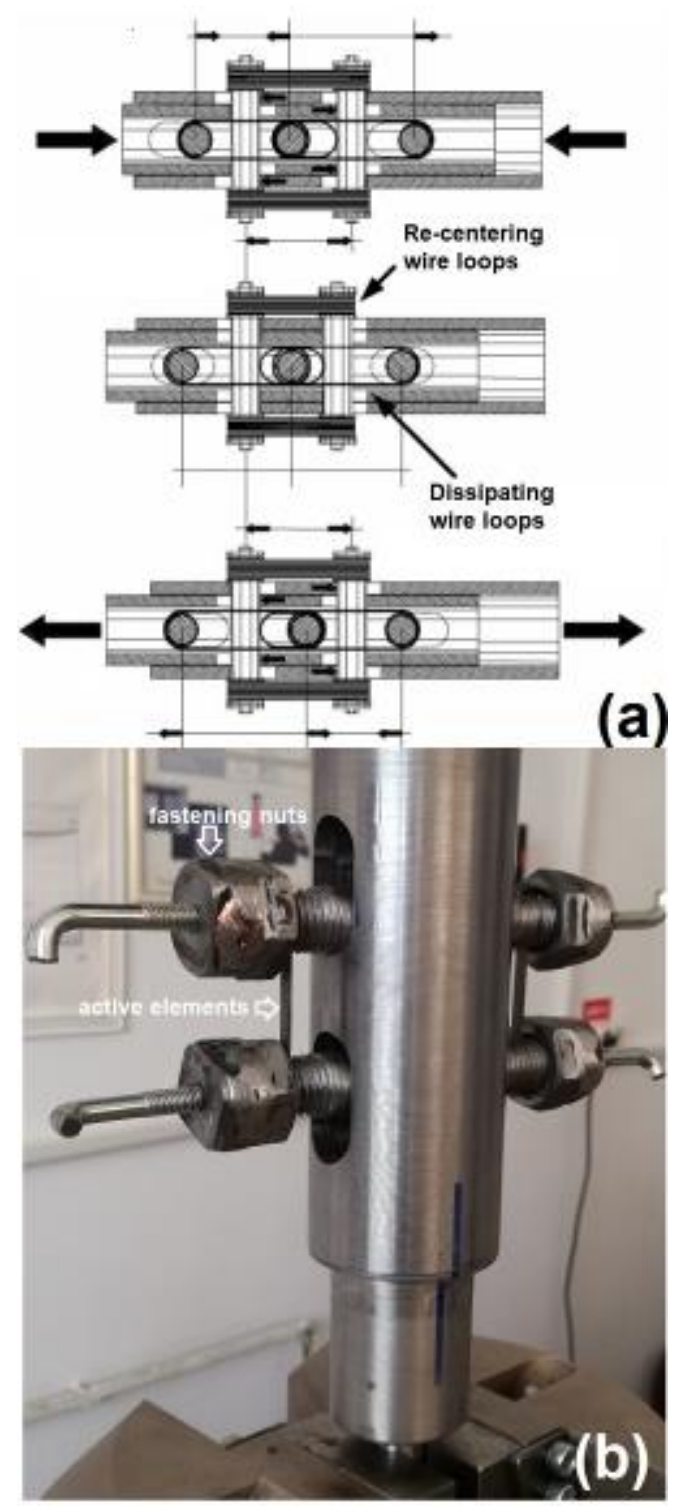

Fig. 1. Experimental setup for testing antiseismic damping capacity. (a) functioning scheme of a complete device developed by Dolce et al. [22]; (b) prototype of re-centering antiseismic damper using 2 flat specimens instead of wire loops 
Figure 1 illustrates both the functioning principle of Dolce's damper that converts either tensile or compressive external solicitations into tensile stresses, or the experimental device, itself, where flat "dog-bone" specimens, representing the active elements, are fixed into the transversal rods, by means of fastening nuts. For damping tests performance, the anti-seismic damper, with a couple of "dog bone" specimens, was fastened in an INSTRON 8801 testing machine and subjected to tension-compression tests, with a frequency of $1 \mathrm{~Hz}$, up to three maximum forces: $3 \mathrm{kN}, 4.4 \mathrm{kN}$ and 5.8 $\mathrm{kN}$.

Couples of "dog-bone" specimens were fastened within the experimental anti-seismic damper and subjected to dynamic tensile-compressive cycles, at the frequency of $1 \mathrm{~Hz}$, which is characteristic to earthquakes.

On the recorded strains-stress curves, the area between loading and unloading curves was calculated for each dynamic cycle and, since it represents mechanical hysteresis, was plotted against the number of cycles and maximum applied force.

\section{Experimental results and discussion}

In order to discuss the effects of solution treatment time on the dynamic response of heattreated specimens, the DMA-SS-3PB strain sweep diagrams, illustrating the variations of internal friction with strain amplitude, recorded with the frequency of $1 \mathrm{~Hz}$, were summarized in Figure 2.

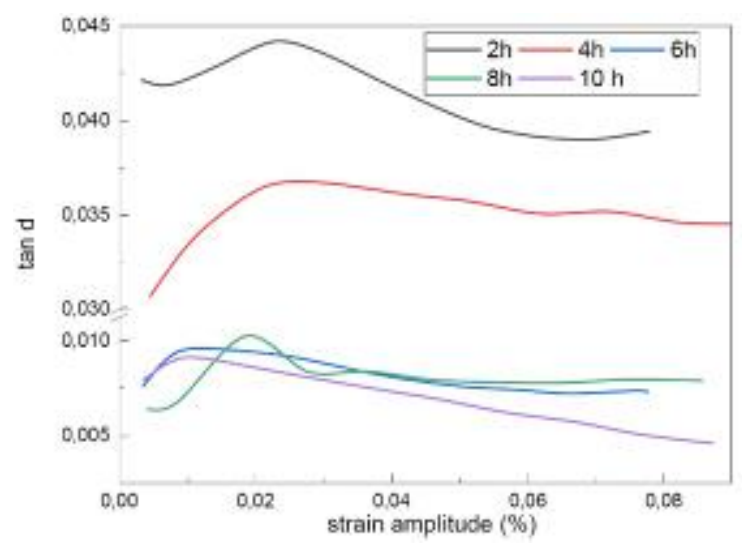

Fig. 2. Strain sweeps three-point-bending DMA diagrams illustrating the variation of average values of internal friction (tan d) with strain amplitude for specimens solution treated for different holding periods

It is noticeable that internal friction $(\tan d)$ is only slightly influenced by strain amplitude increase for all the specimens. In addition, the specimens solution treated for 2 and 4 hours experienced the largest tan $\mathrm{d}$ values, reaching almost 0.045 . Another important point is that the specimens that were solution treated for 6,8 and 10 hours experience very low values of internal friction, typically less than 0.01. It is obvious that the solution treatments for 2 and 4 hours caused different structural changes as compared to those applied for 6,8 and 10 hours. It follows that solution treatment for 2 and 4 hours caused microstructures that enable high mobility of the interfaces while the three others did not. These results recommended the use of specimens solution treated with 2 h-holding at $1050{ }^{\circ} \mathrm{C}$ for further experiments.

In order to identify the particularities of the structure of these specimens, XRD patterns were recorded, as summarized in Figure 3. The specimens solution treated for 2 hours had different structure, as compared to the other ones. Phase indexing was performed based on the crystallographic databases and the results are displayed in Figure 3. The specimen solution treated for 2 hours contains $\varepsilon$-hcp martensite, under the form of (101) variant. The rest of the structure comprises small amounts of $\alpha^{\prime}$-bcc martensite plate variants.

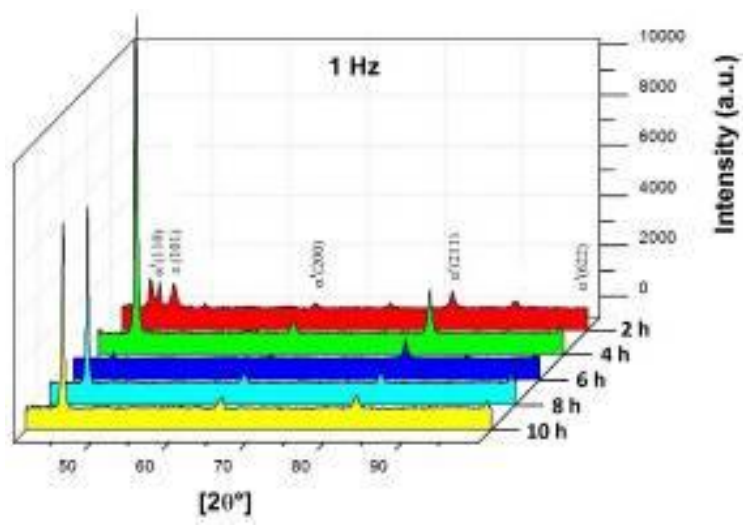

Fig. 3. XRD patterns of Fe-28Mn-6Si-5Cr SMA specimens solution treated at $1050^{\circ} \mathrm{C}$ for different holding periods

The low values of internal friction can be associated with the presence of at several martensite plate variants of $\alpha^{\prime}$-bcc martensite, namely (110), (200), (211) and (622). The high mobility of the interfaces of $\varepsilon$-hcp martensite causes elevated mean values of internal friction, as reported by Chung et al. [24]. The typical morphology of $\varepsilon$-hcp martensite is shown by the SEM in Figure 4.

$\varepsilon$-hcp martensite is very narrow and long and develop the so-called "triangular morphology" due to the orientation along $<111>\gamma$ close-packed planes.

Three couples of specimens solution treated for 2 hours were tested by means of the anti-seismic 
damper, subjected to tension-compression cycles at the frequency of $1 \mathrm{~Hz}$. Each couple was tested up to different maximum forces. The stress-strain diagrams are shown in Figure 5.

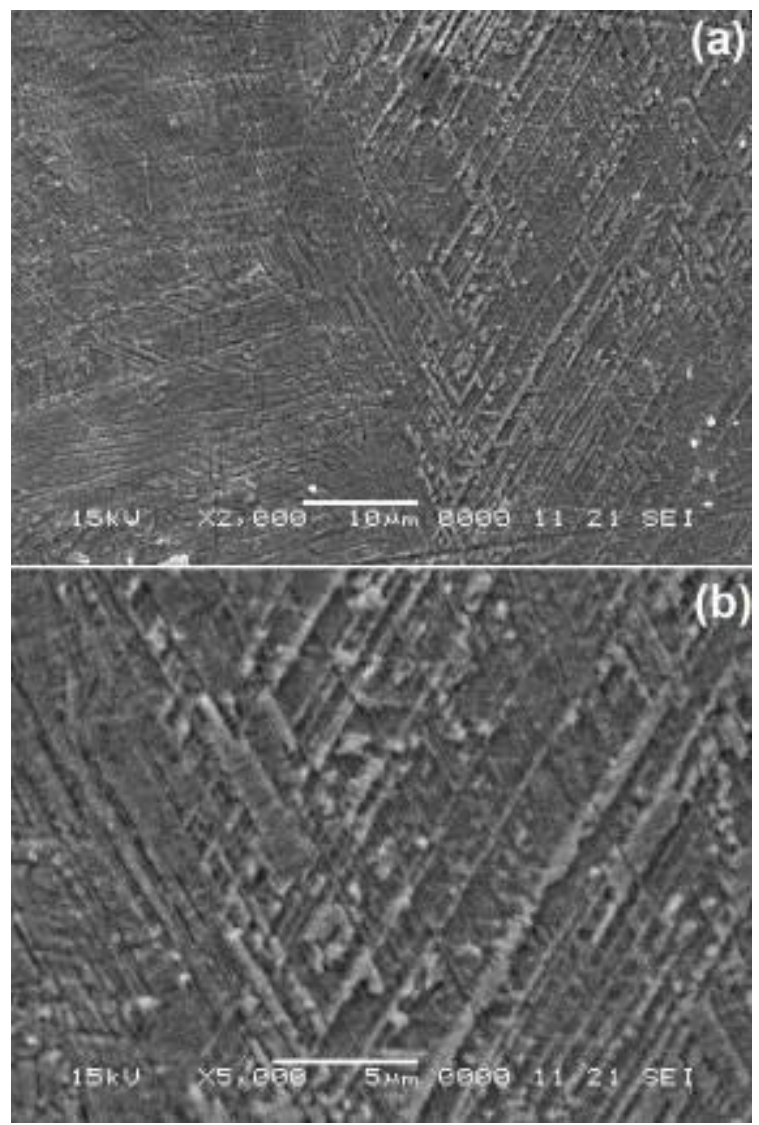

Fig. 4. SEM micrographs of Fe-28Mn-6Si-5Cr SMA specimens solution treated at $1050^{\circ} \mathrm{C}$ for 2 hours: (a) general aspect; (b) detail of $\varepsilon$-hcp martensite plates with triangular morphology

It is obvious that both strain and stress increased with the maximum applied force. During dynamic testing, the specimens became more and more elongated, but strain increase/ cycle diminished with increasing the number of cycles. Unlike DMA-SS3PB tests, the largest amount of energy was absorbed during the first cycle, so it was considered for damping analysis. Since internal friction is proportional with mechanical hysteresis, the area between loading and unloading portions of the curves can determine the amount of absorbed energy. These values, determined by integration, are summarized in Figure 6.

The largest amount of energy, over 108 $\mathrm{mJ} / \mathrm{mm}^{3}$, was absorbed in the first cycle applied up to $5.8 \mathrm{kN}$. Subsequently, the amount of absorbed energy became less and less, thus that in the fifth cycle the three couple of specimens experienced similar damping behaviors.

The anti-seismic damper was tested up to $4 \mathrm{kN}$ for a number of 40,000 cycles, which would correspond to an earthquake lasting for more than 11 hours (at $1 \mathrm{~Hz}$ frequency). Figure 7 shows the loaddisplacement curves of the last cycles.
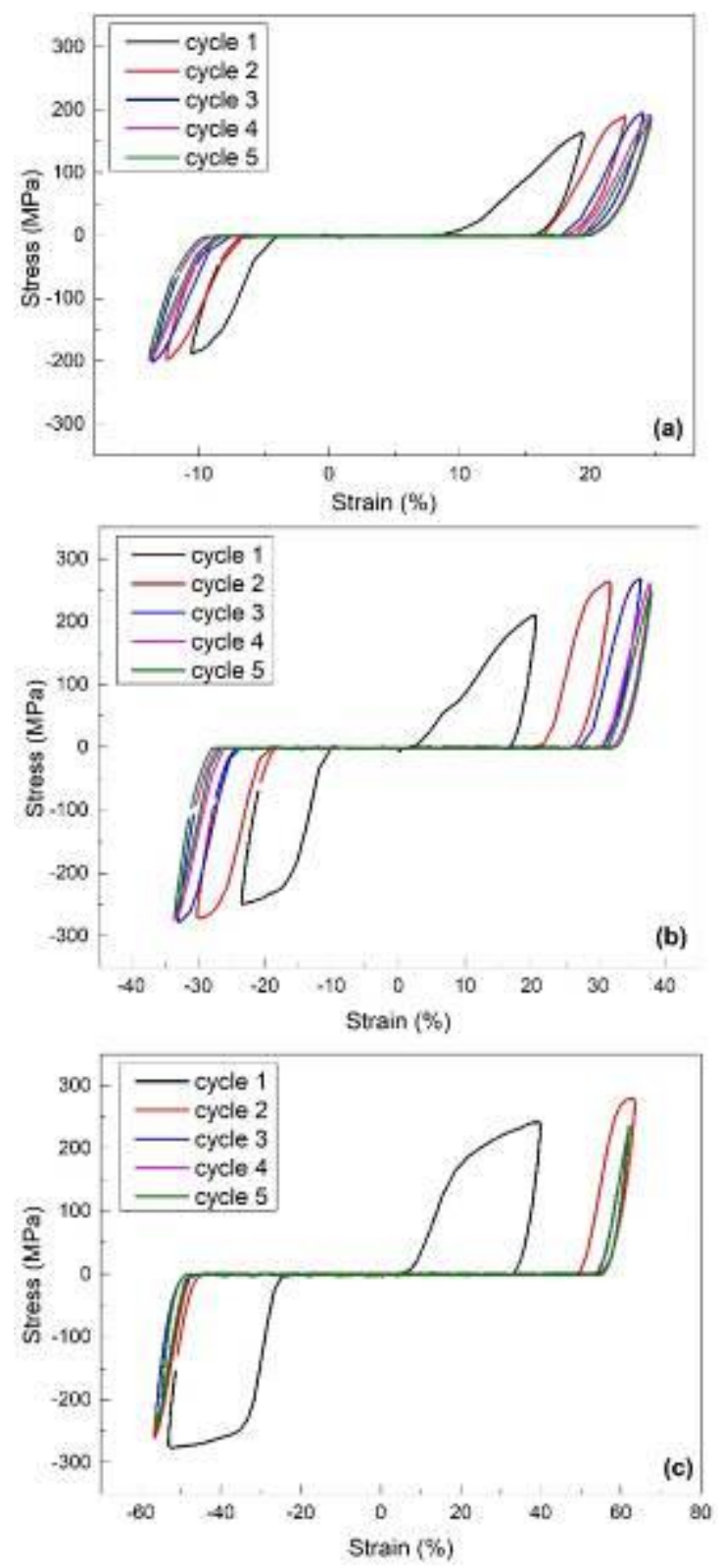

Fig. 5. Stress-strain curves recorded by the tensile testing machine during elongationcompression tests of two Fe-28Mn-6Si-5Cr SMA specimens solution treated at $1050^{\circ} \mathrm{C}$ for 2 hours, fastened on the anti-seismic damper, from Figure 1. Each couple of specimens was tested at $1 \mathrm{~Hz}$ for different maximum forces: (a) $3 \mathrm{kN}$; (b) $4.4 \mathrm{kN}$; (c) $5.8 \mathrm{kN}$ 

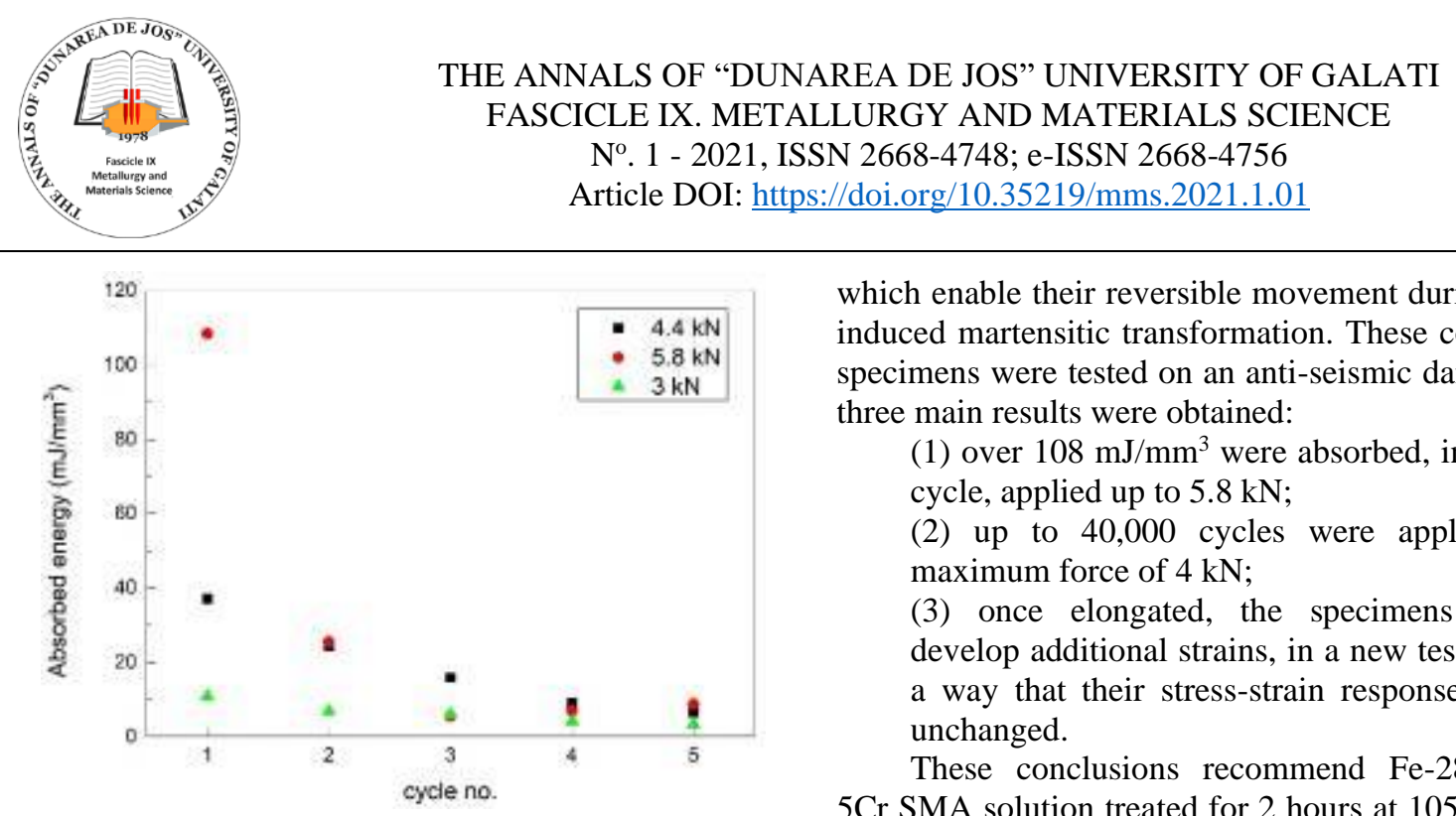

Fig. 6. Variation of absorbed energy during the first five elongation-compression cycles illustrated in Figure 5

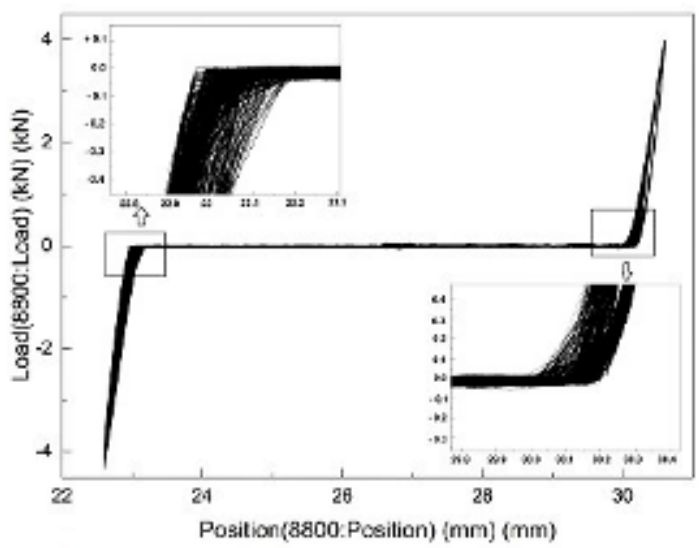

Fig. 7. Load-displacement records during the last part of 40,000 cycles, up to $4 \mathrm{kN}$, with details of the beginning and the end of load plateaus

As expected, the curves resemble those of the fifth cycles from Figure 5. The magnified details of the two ends of the load plateau show that mechanical hysteresis was reduced due to the initial elongation of the specimens. In addition, if an elongated couple of specimens is tested for the second time, no differences were noticed between the first, the tenth and the hundredth cycles.

\section{Conclusions}

The results have shown that $\mathrm{Fe}-28 \mathrm{Mn}-6 \mathrm{Si}-5 \mathrm{Cr}$ SMA experienced internal friction as high as 0.045 , determined by DMA-SS-3PB after solution treatment for 2 hours at $1050{ }^{\circ} \mathrm{C}$. This behavior was associated, by means of XRD pattern, with the presence of $\varepsilon$-hcp martensite, which has, on SEM micrographs, a morphology consisting of long narrow plate variants

which enable their reversible movement during stress induced martensitic transformation. These couples of specimens were tested on an anti-seismic damper and three main results were obtained:

(1) over $108 \mathrm{~mJ} / \mathrm{mm}^{3}$ were absorbed, in the first cycle, applied up to $5.8 \mathrm{kN}$;

(2) up to 40,000 cycles were applied at a maximum force of $4 \mathrm{kN}$;

(3) once elongated, the specimens do not develop additional strains, in a new test, in such a way that their stress-strain response remains unchanged.

These conclusions recommend $\mathrm{Fe}-28 \mathrm{Mn}-6 \mathrm{Si}$ 5Cr SMA solution treated for 2 hours at $1050^{\circ} \mathrm{C}$ as a potential candidate for the development of active elements for anti-seismic dampers.

\section{References}

[1]. Maki T., Ferrous shape memory alloys, in Shape Memory Materials, (Otsuka, K. and Wayman, C.M., eds.), Cambridge University Press, p. 117-132, 1998.

[2]. Dong Z. Z., Kajiwara S., Kikuchi T., Sawaguchi T., Effect of pre-deformation at room temperature on shape memory properties of stainless type $\mathrm{Fe}-15 \mathrm{Mn}-5 \mathrm{Si}-9 \mathrm{Cr}-5 \mathrm{Ni}-(0.5-1.5) \mathrm{NbC}$ alloys, Acta Mater., 53, p. 4009-4018, 2005.

[3]. Bujoreanu L. G., Dia V., Stanciu S., Susan M., Baciu C., Study of the tensile constrained recovery behavior of a $\mathrm{Fe}-\mathrm{Mn}-\mathrm{Si}$ shape memory alloy, Eur. Phys. J. Special Topics, 158, p. 15-20, 2008.

[4]. James R. D., Hane K. F., Martensitic transformations and shape-memory materials, Acta Mater., 48, p. 197-222, 2000.

[5]. Bergeon N., Guenin G., Esnouf C., Microstructural analysis of the stress-induced $\varepsilon$ martensite in a Fe-Mn-Si-Cr-Ni shape memory alloy: Part II: Transformation reversibility, Mater. Sci. Eng. A, 242, p. 87-95, 1998.

[6]. Murakami M., Suzuki H., Nakamura Y., Effect of silicon on the shape memory effect of polycrystalline Fe-Mn-Si alloys, Trans. ISIJ 27:B87, 1987.

[7]. Kajiwara S., Characteristic features of shape memory effect and related transformation behavior in Fe-based alloys, Mat. Sci. Eng. A, 273-275, p. 67-88, 1999.

[8]. Bracke L., Mertens G., Penning J., De Cooman B. C., Liebherr M., Akdut N., Influence of phase transformations on the mechanical properties of high-strength austenitic Fe-Mn-Cr steel, Metall. Mater. Trans. A, 37A, p. 307-317, 2006.

[9]. Arruda G. J., Buono V. T. L., Andrade M. S., The influence of deformation on the microstructure and transformation temperatures of $\mathrm{Fe}-\mathrm{Mn}$-Si-Cr-Ni shape memory alloys, Mater. Sci. Eng. A, 273-275, p. 528-532, 1999.

[10]. Li J. C., Zhao M., Jiang Q., Alloy design of $\mathrm{Fe}-\mathrm{Mn}-\mathrm{Si}-\mathrm{Cr}-\mathrm{Ni}$ shape-memory alloys related to stacking-fault energy, Metall. Mater. Trans. A, 31(3), p. 581-584, 2000.

[11]. Otsuka H., Fe-Mn-Si Based Shape Memory Alloys, MRS Proceedings, 246, 309, doi:10.1557/PROC-246, p. 309-320, 1991. [12]. Druker A. V., Perotti A., Esquivel I., Malarría J., A manufacturing process for shaft and pipe couplings of $\mathrm{Fe}-\mathrm{Mn}$-Si$\mathrm{Ni}$-Cr shape memory alloy, Mater. Design, 56, p. 878-888, 2014.

[13]. Maruyama T., Kurita T., Kozaki S., Andou K., Farjami S., Kubo H., Innovation in producing crane rail fishplate using $\mathrm{Fe}-\mathrm{Mn}$-Si-Cr based shape memory alloy, Mater. Sci. Technol., 24, p. $908-912,2008$

[14]. Sawaguchi T., Kikuchi T., Ogawa K., Kajiwara S., Ikeo Y., Kojima M., Ogawa T., Development of prestressed concrete using $\mathrm{Fe}$-Mn-Si-based shape memory alloys containing $\mathrm{NbC}$, Mater. Trans. 47, p. 580-583, 2006. 


\section{THE ANNALS OF "DUNAREA DE JOS” UNIVERSITY OF GALATI \\ FASCICLE IX. METALLURGY AND MATERIALS SCIENCE \\ No $^{\circ} .1$ - 2021, ISSN 2668-4748; e-ISSN 2668-4756 \\ Article DOI: https://doi.org/10.35219/mms.2021.1.01}

[15]. Shahverdi M., Czaderski C., Motavalli M., Iron-based shape memory alloys for prestressed near surface mounted strengthening of reinforced concrete beams, Constr. Build. Mater. P. 11228-11238, 2016.

[16]. Sawaguchi T., Maruyama T., Otsuka H., Kushibe A., Inoue Y., Tsuzaki K., Design Concept and Applications of FeMnSi-Based Alloys from Shape-Memory to Seismic Response Control, Mater. Trans., 57(3), p. 283-293, 2016.

[17]. Otsuka H., Yamada H., Maruyama T., Tanahashi H., Matsuda S., Murakami M., Effects of alloying additions on $\mathrm{Fe}$ Mn-Si shape memory alloys, Trans. ISIJ 30, p. 674-679, doi: 10.2355/isijinternational. 30.674, 1990.

[18]. Sawaguchi T., Sahu P., Kikuchi T., Ogawa K., Kajiwara S., Kushibe A., Higashino M., Ogawa T., Vibration mitigation by the reversible fcc/hcp martensitic transformation during cyclic tension-compression loading of an $\mathrm{Fe}-\mathrm{Mn}$-Si-based shape memory alloy, Scripta Mater., 54, p. 1885-1890, 2006.

[19]. Bidaux J.-E., Schaller R., Benoit W., Study of hcp-fcc phase transition in Cobalt by acoustic measurements, Acta Metall., 37(3), p. 803-811, 1989.
[20]. De A. K., Cabanas N., De Cooman B. C., Fcc-hcp Transformation-Related Internal Friction in Fe-Mn Alloys, Z. Metallkd., 93, p. 228-235, 2002.

[21]. Popa M., Lohan N. M., Popa F., Pricop B., Bujoreanu L. G., Holding-temperature effects on thermally and stress insudec martensitic tranasformations in an FeMnSiCrNi SMA, Mater. Today Proced., 19, p. 956-962, 2019.

[22]. Dolce M., Cardone D., Marnetto R., Implementation and testing of passive control devices based on shape memory alloys, Earthquake Engng Struct Dyn 29, p. 945-968, 2000.

[23]. Paleu V., Gurău G., Comăneci R. I., Sampath V., Gurău C., Bujoreanu L. G., A new application of $\mathrm{Fe}-28 \mathrm{Mn}-6 \mathrm{Si}-5 \mathrm{Cr}$ (mass\%) shape memory alloy, for self-adjustable axial preloading of ball bearings, Smart Materials and Structures, 27(7), 075026, (11pp), 2018.

[24]. Chung C. Y., Chen Shuchuan, Hsu T. Y., Thermomechanical training behavior and its dynamic mechanical analysis in an $\mathrm{Fe}-\mathrm{Mn}$-Si shape memory alloy, Materials Characterization, 37(4), p. 227-236, 1996. 